ISSN 2412-608X. МАСЛИЧНЫЕ КУЛЬТУРЫ. Научно-технический бюллетень Всероссийского научно-исследовательского института масличных культур. Вып. 2 (174), 2018

\section{УДК 633.853.52:631.52}

DOI 10.25230/2412-608X-2018-2-174-148-151

\section{ОЧЕНЬ РАННИЙ СОРТ СОИ ПУМА}

\section{С.В. Зеленцов,}

доктор сельскохозяйственных наук

Е.В. Мошненко,

кандидат биологических наук

А.А. Ткачёва

кандидат сельскохозяйственных наук

С.А. Рамазанова,

кандидат биологических наук

М.В. Трунова,

кандидат биологических наук

Е.Н. Будников,

старший научный сотрудник

\section{Л.А. Бубнова,}

младший научный сотрудник

\section{ФГБНУ ВНИИМК}

Россия, 350038, г. Краснодар, ул. им. Филатова, д. 17

Тел.: (861) 275-78-45

E-mail: soya@vniimk.ru

Для цитирования: Зеленцов С.В., Мошненко Е.В., Ткачёва А.А., Рамазанова С.А., Трунова М.В., Будников Е.Н., Бубнова Л.А. Очень ранний сорт сои Пума // Масличные культуры. Научно-технический бюллетень Всероссийского научно-исследовательского института масличных культур. - 2018. Вып. 2 (174). - С. 148-151.

Ключевые слова: соя, повышенная урожайность, скороспелость, засухоустойчивость, молекулярный паспорт.

Очень ранний сорт сои Пума выведен методом индивидуального отбора из гибридной популяции $\mathrm{F}_{4}$ Альба $\times$ Припять. По результатам сортоиспытания 2014-2016 гг. сорт Пума по урожайности превысил стандартный очень ранний сорт Лира на 0,11 т/га. Растения нового сорта отличаются повышенной засухоустойчивостью, устойчивы к полеганию и растрескиванию бобов. Высота растений на широте Краснодара $\left(45^{\circ}\right) 75-95$ см. Сорт отличается повышенной засухоустойчивостью. Это позволяет его возделывать на зерно в основных посевах практически во всех соепроизводящих хозяйствах Южного, Центральночернозёмного и Приволжского федеральных округов на географических широтах от 43 до $52^{\circ}$.
UDC 633.853.52:631.52

A very early-ripening soybean variety Puma.

S.V. Zelentsov, doctor of agriculture

E.V. Moshnenko, $\mathrm{PhD}$ in biology

A.A. Tkachyova, $\mathrm{PhD}$ in agriculture

S.A. Ramazanova, $\mathrm{PhD}$ in biology

M.V. Trunova, $\mathrm{PhD}$ in biology

E.N. Budnikov, senior researcher

L.A. Bubnova, junior researcher

All-Russian Research Institute of Oil Crops by the name of Pustovoit V.S. (VNIIMK)

17 Filatova str., Krasnodar, 350038, Russia

Tel.: (861) 275-78-45

E-mail: soya@vniimk.ru

Key words: soybean, increased productivity, early ripening, drought resistance, molecular passport.

A very early-ripening soybean variety Puma is developed by the method of individual selection from the hybrid population of $\mathrm{F}_{4}$ Alba $\times$ Pripyat. Based on the results of the variety testing in 2014-2016, Puma yields exceeded the standard very early-ripening variety Lira by $0.11 \mathrm{t}$ per ha. Plants of the new variety are distinguished by high drought resistance, they are resistant to lodging and pod shattering. The height of plants at the latitude of Krasnodar $\left(45^{\circ}\right)$ is $75-95 \mathrm{~cm}$. The variety is characterized by an increased drought resistance. This allows its cultivation for grain in the spring sowing nearly in all soybean-producing farms of the Southern, Central Chernozem and Volga federal districts on geographic widths from 43 to $52^{\circ}$.

Значительная доля посевов сои в России расположена в климатических зонах с неблагоприятными для культуры значениями, как минимум, одного из основных климатических параметров: продолжительности безморозного периода, сумм эффективных температур, годовых сумм осадков и сезонного распределения их выпадения, гидротермического коэффициента, а также ещё целого ряда дополнительных агроклиматических показателей $[4 ; 6]$. Поэтому именно неблагоприятные климатические условия Российской Федерации, особенно её азиатской части, определяют пониженную продуктивность сои по сравнению с североамериканскими, латиноамериканскими и западноевропейскими странами $[1 ; 6]$.

Наиболее частыми аномальными явлениями на юге России являются длительные засушливые периоды во второй половине лета. Поэтому с целью адаптации сельскохозяйственного производства 
к складывающимся изменениям климата к современным и перспективным сортам сои предъявляются повышенные требования к продуктивности в засушливых условиях $[1 ; 4 ; 6] . \quad$ В связи с этим современная селекция сои в России, помимо обязательной селекции на урожай, также направлена на повышение климатической адаптивности к основным зонам возделывания культуры, в т.ч. за счёт сокращения вегетационного периода (раннеспелости) и повышения засухоустойчивости $[1 ; 4 ; 5]$.

Основными зонами промышленного возделывания сортов сои селекции ФГБНУ ВНИИМК традиционно являются южные регионы России, в т.ч. с дефицитом летних осадков. Поэтому все сорта сои ВНИИМК отличаются повышенной адаптивностью к засушливым условиям. Одним из эффективных способов ухода от засух, помимо орошения, является селекция ранних и очень ранних сортов, позволяющих сформировать урожай до пиков позднелетних засух [5; 6].

Примером создания очень раннего и в то же время урожайного и засухоустойчивого сорта является линия Л-374 селекции ФГБНУ ВНИИМК. Основой линии Л-374 послужило элитное растение, выделенное в 2010 г. в расщепляющейся гибридной популяции $\mathrm{F}_{4}$ Альба $\times$ Припять. Под коммерческим названием «Пума» линия Л-374 в 2016 г. была передана на Государственное сортоиспытание.

Урожайность очень раннего сорта сои Пума в предварительном и конкурсном сортоиспытании была стабильно выше (в 2016 г. статистически достоверно) по сравнению с очень ранним сортомстандартом Лира (табл. 1).

\section{Таблица 1}

Характеристика очень раннего сорта Пума

ЦЭБ ВНИИМК, 2014-2016 гг.

\begin{tabular}{|c|c|c|c|c|c|}
\hline \multirow[b]{2}{*}{ Сорт } & \multirow{2}{*}{$\begin{array}{c}\text { Вегетаци- } \\
\text { онный } \\
\text { период, } \\
\text { сут. }\end{array}$} & \multicolumn{4}{|c|}{ Урожайность, т/га } \\
\hline & & $\begin{array}{c}2014 \\
\text { Г. }\end{array}$ & $\begin{array}{c}2015 \\
\text { Г. }\end{array}$ & $\begin{array}{c}2016 \\
\text { Г. }\end{array}$ & среднее \\
\hline Пума & 91 & 2,95 & 2,08 & 1,78 & 2,27 \\
\hline Лира (стандарт) & 94 & 2,87 & 2,01 & 1,59 & 2,16 \\
\hline $\begin{array}{l}\text { Отклонение от } \\
\text { стандарта, } \pm\end{array}$ & +3 & $+0,08$ & $+0,07$ & $+0,19$ & $+0,11$ \\
\hline $\mathrm{HCP}_{05}$ & - & 0,25 & 0,22 & 0,14 & - \\
\hline
\end{tabular}

Вегетационный период нового сорта на широте Краснодара $\left(45^{\circ}\right)$ в зависимости от метеоусловий года варьировал от 91 до 96 суток и в среднем за период 20142016 гг. составил 93 дня. Очень раннее созревание сорта Пума позволяет возделывать его на зерно в основных посевах практически во всех соепроизводящих хозяйствах Южного, Центрально-Чернозёмного и Приволжского федеральных округов на широтах до 50-52 .

Высота растений сорта Пума на широте Краснодара от 75 до 95 см, нижние бобы при оптимальной густоте стояния растений (350-400 тыс. раст./га) располагаются на высоте 13-15 см от поверхности почвы (рис. 1). Во влажные годы и на более высоких географических широтах $\left(50-52^{\circ}\right)$ высота растений может увеличиться до 100-120 см.

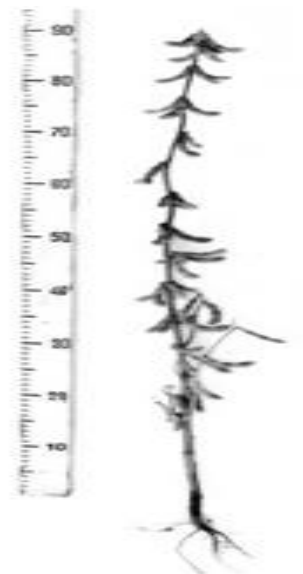

Рисунок 1 - Растение сорта Пума

Тип развития куста по международному классификатору UPOV - от полудетерминантного до индетерминантного [7]. По усовершенствованному сотрудниками ВНИИМК классификатору типов роста сои [3], сорт Пума отличается полудетерминантным (полуограниченным) типом роста (код типа роста - SD3), завершающимся в период начала формирования семян.

По внутривидовой классификации сои, разработанной во ВНИИМК, сорт Пума относится к среднестебельному сортотипу - cc. medicaulis Zel. et Koch. северокавказской эколого-географической группы маньчжурского подвида сои ssp. manshurica (Enken) Zel. et Koch. [2]. Pacтения сорта Пума устойчивы к полеганию 
и преждевременному вскрытию (растрескиванию) бобов при длительном перестое на корню.

Опушение растений рыжевато-коричневое. Окраска бобов коричневая. Окраска венчика цветка фиолетовая. Семенная оболочка жёлтая, в оптимальных условиях созревания без пигментации (рис. 2).

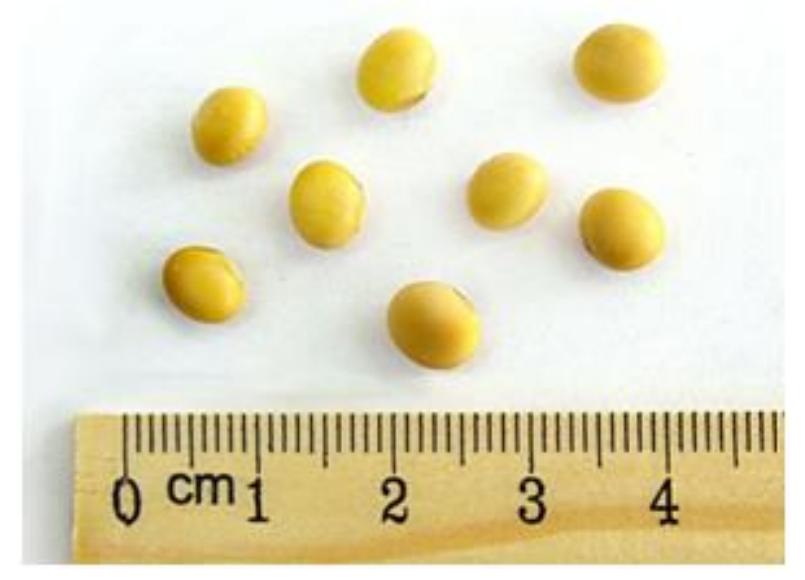

Рисунок 2 - Размеры, форма и окраска семян сорта Пума

В острозасушливые годы и на фоне пониженных температур на оболочке семян из верхних узлов растений может формироваться коричневая пигментация. Рубчик семени серый, с варьированием от почти бесцветного до тёмно-серого в зависимости от погодных условий в период налива и созревания семян.

При выращивании сорта Пума на богаpe, особенно в условиях интенсивных засух, масса 1000 семян составляет 131-153 г. В годы с достаточным количеством осадков в фазы формирования и налива семян и на орошении масса 1000 семян этого сорта может увеличиться до 160-180 г. Сорт устойчив к недостаточному влагообеспечению, фузариозу и пепельной гнили.

Содержания белка в семенах этого сорта составляет 37,7-41,6 \%. Содержание масла в семенах варьирует от 22,1 до 23,3 \% (табл. 2).
Таблица 2

Биохимическая характеристика семян сорта Пума

ЦЭБ ВНИИМК, 2015-2016 гг.

\begin{tabular}{|l|c|c|c|c|c|c|}
\hline \multirow{2}{*}{ Сорт } & \multicolumn{2}{|c|}{ Содержание белка, \% } & \multicolumn{2}{c|}{ Содержание масла, \% } \\
\cline { 2 - 7 } & $\begin{array}{c}2015 \\
\text { г. }\end{array}$ & $\begin{array}{c}2016 \\
\text { г. }\end{array}$ & $\begin{array}{c}\text { сред- } \\
\text { нее }\end{array}$ & $\begin{array}{c}2015 \\
\text { г. }\end{array}$ & $\begin{array}{c}2016 \\
\text { г. }\end{array}$ & $\begin{array}{c}\text { сред- } \\
\text { нее }\end{array}$ \\
\hline Пума & 41,6 & 37,7 & 39,7 & 22,1 & 23,3 & 22,7 \\
\hline Лира (стандарт) & 41,5 & 37,2 & 39,4 & 21,1 & 23,8 & 22,5 \\
\hline $\begin{array}{l}\text { Отклонение от } \\
\text { стандарта, } \pm\end{array}$ & $+0,1$ & $+0,5$ & $+0,3$ & 1,0 & $-0,5$ & $+0,2$ \\
\hline
\end{tabular}

Для сорта сои Пума разработан генетический паспорт на основе анализа ДНК с использованием 8 микросателлитных SSR-локусов (табл. 3). Методика проведения анализа и характеристика маркерных локусов описаны в ранее опубликованных статьях [8; 9].

Таблица 3

Молекулярный паспорт сорта сои Пума

ЦЭБ ВНИИМК, 2017 г.

\begin{tabular}{|l|c|c|}
\hline \multicolumn{1}{|c|}{ Локус } & Аллели & $\begin{array}{c}\text { Молекулярный } \\
\text { вес (п.н.) }\end{array}$ \\
\hline Satt1 & 2 & $141-150$ \\
\hline Satt 2 & 2 & $140-152$ \\
\hline Satt5 & 1,2 & $157-177$ \\
\hline Soypr 1 & 1 & $163-188$ \\
\hline Sat 1 & 3 & $188-235$ \\
\hline Sat 36 & 2 & $115-185$ \\
\hline Sat43 & 3 & $157-203$ \\
\hline Soyhsp176 & 3 & $118-135$ \\
\hline
\end{tabular}

Нумерацию микросателлитных аллелей по каждому локусу проводили следующим образом: фрагмент ДНК с максимальным значением молекулярного веса обозначали цифрой 1 и далее по мере уменьшения молекулярного веса цифрами 2 и 3. По локусу Satt5 выявлен полиморфизм внутри сорта, то есть присутствуют генотипы с аллелями 1 и 2. Молекулярный вес амплифицированных фрагментов расположен в определённом интервале, характерном для каждой праймерной пары.

При нумерации микросателлитных аллелей по каждому локусу фрагмент ДНК с максимальным значением молекулярного веса обозначали цифрой 1 и далее, по мере уменьшения молекулярного веса, цифрами 2 и 3. Молекулярный вес амплифицированных аллелей расположен в 
определённом интервале, характерном для каждой праймерной пары (см. табл. 3).

В целом очень ранний сорт сои Пума отличается высокой, для своей группы спелости, урожайностью и засухоустойчивостью, что в сочетании с высокой устойчивостью к преждевременному вскрытию бобов, определяет его потенциальную коммерческую привлекательность для сельхозтоваропроизводителей и переработчиков сои. Сорт Пума был передан в 2016 г. на Государственное сортоиспытание по Центрально-Чернозёмному, Северо-Кавказскому и Нижневолжскому регионам (5, 6 и 8 зоны).

\section{Список литературы}

1. Зайщеев Н.И., Бочкарёв Н.И., Зеленичов С.В. Перспективы и направления селекции сои в России в условиях реализации национальной стратегии импортозамещения // Масличные культуры. Науч.тех. бюл. ВНИИМК. - 2016. - Вып. 2 (166). - С. 3-11.

2. Зеленцов С.В., Кочегура А.В. Современное состояние систематики культурной сои Glycine max (L.) Merrill // Масличные культуры. Науч.-тех. бюл. ВНИИМК. - 2006. - Вып. 1 (134). - С. 34-48.

3. Зеленцов С.В., Лучинский А.С. Усовершенствованная классификация типов роста сои // Масличные культуры. Науч.-тех. бюл. ВНИИМК, 2011. Вып. 2 (148-149). - С. 88-94.

4. Зеленияов С.В., Мошненко Е.В. Пути адаптации сельского хозяйства России к глобальным изменениям климата на примере экологической селекции сои // Научный диалог. Естествознание и экология. - 2012. - № 7. - С. 40-59.

5. Лукомеи В.М., Бочкарёв Н.И., Зеленцов С.В., Мошненко E.B. Создание сортов сои с расширенной адаптацией к изменяющемуся климату Западного Предкавказья // Труды Кубанского государственного аграрного университета. - 2012. - Т. 1. - № 35. - С. 248-254.

6. Лукомец В.М., Зеленцов С.В., Кривошлыков K.M. Перспективы и резервы расширения производства масличных культур в Российской Федерации // Масличные культуры. Науч.-тех. бюл. ВНИИМК. - 2015. - Вып. 4 (164). - С. 81-102.

7. Методика проведения испытаний на отличимость, однородность и стабильность. Соя Glycine max (L.) Merrill). Утв. Председателем ФГУ «Государственная комиссия Российской Федерации по испытанию и охране селекционных достижений» В.В. Шмаль, № 12-06/21 от 30.10.2006 г.: [Электронный ресурс]. - URL: http://gossort.com/ metodic/R0080.zip (дата обращения: 18.02.2018).

8. Рамазанова C.A. Идентификация генотипов сои разного происхождения с использованием полиморфизма девяти микросателлитных локусов
ДНК // Современные проблемы селекции и технологии возделывания сои // Сб. статей 2-й международной конференции по сое. - Краснодар, 9-10 сентября 2008 г. - С. 129-136.

9. Рамазанова С.А. Идентификация сортов сои (Glycine $\max$ L.) с использованием микросателлитных локусов ДНК // Масличные культуры. Науч.тех. бюл. ВНИИМК. - 2016. - Вып. 2 (166). - С. 63-67.

\section{References}

1. Zaytsev N.I., Bochkarev N.I., Zelentsov S.V. Perspektivy i napravleniya selektsii soi v Rossii v usloviyakh realizatsii natsional'noy strategii importozameshcheniya // Maslichnye kul'tury. Nauch.tekh. byul. VNIIMK. - 2016. - Vyp. 2 (166). - S. 3-11.

2. Zelentsov S.V., Kochegura A.V. Sovremennoe sostoyanie sistematiki kul'turnoy soi Glycine max (L.) Merrill // Maslichnye kul'tury. Nauch.-tekh. byul. VNIIMK. - 2006. - Vyp. 1 (134). - S. 34-48.

3. Zelentsov S.V., Luchinskiy A.S. Usovershenstvovannaya klassifikatsiya tipov rosta soi // Maslichnye kul'tury. Nauch.-tekh. byul. VNIIMK, 2011. - Vyp. 2 (148-149). - S. 88-94.

4. Zelentsov S.V., Moshnenko E.V. Puti adaptatsii sel'skogo khozyaystva Rossii k global'nym izmeneniyam klimata na primere ekologicheskoy selektsii soi // Nauchnyy dialog. Estestvoznanie i ekologiya. - 2012. - № 7. - S. 40-59.

5. Lukomets V.M., Bochkarev N.I., Zelentsov S.V., Moshnenko E.V. Sozdanie sortov soi s rasshirennoy adaptatsiey $\mathrm{k}$ izmenyayushchemusya klimatu Zapadnogo Predkavkaz'ya // Trudy Kubanskogo gosudarstvennogo agrarnogo universiteta. -2012 . $-\mathrm{T}$. 1. - № 35. - S. 248-254.

6. Lukomets V.M., Zelentsov S.V., Krivoshlykov K.M. Perspektivy i rezervy rasshireniya proizvodstva maslichnykh kul'tur v Rossiyskoy Federatsii // Maslichnye kul'tury. Nauch.-tekh. byul. VNIIMK. 2015. - Vyp. 4 (164). - S. 81-102.

7. Metodika provedeniya ispytaniy na otlichimost', odnorodnost' i stabil'nost'. Soya Glycine max (L.) Merrill). Utv. Predsedatelem FGU «Gosudarstvennaya komissiya Rossiyskoy Federatsii po ispytaniyu i okhrane selektsionnykh dostizheniy» V.V. Shmal', № $12-06 / 21$ ot 30.10 .2006 g. : [Elektronnyy resurs]. URL: http://gossort.com/metodic/R0080.zip (data obrashcheniya: 18.02.2018).

8. Ramazanova S.A. Identifikatsiya genotipov soi raznogo proiskhozhdeniya $\mathrm{s}$ ispol'zovaniem polimorfizma devyati mikrosatellitnykh lokusov DNK // Sovremennye problemy selektsii i tekhnologii vozdelyvaniya soi // Sb. statey 2-y mezhdunarodnoy konferentsii po soe. - Krasnodar, 9-10 sentyabrya 2008 g. - S. 129-136.

9. Ramazanova S.A. Identifikatsiya sortov soi (Glycine max L.) s ispol'zovaniem mikrosatellitnykh lokusov DNK // Maslichnye kul'tury. Nauch.-tekh. byul. VNIIMK. - 2016. - Vyp. 2 (166). - S. 63-67. 